\title{
EGRESO DE LOS PACIENTES DEL MANICOMIO GENERAL DE LA CASTAÑEDA, (1929-1958) ¿UN PROBLEMA FAMILIAR?
}

\author{
María Teresa Remartínez Martín \\ Investigadora Independiente Egresada Instituto Mora \\ Email: mariateresaremartinez@gmail.com \\ ORCID iD: https://orcid.org/0000-0001-5194-6021
}

Recibido: 30 junio 2020; Aprobado: 26 enero 2021

Cómo citar este artículo/Citation: Remartínez Martín, María Teresa (2021) “Egreso de los pacientes del manicomio general de la Castañeda, (1929-1958) ¿un problema familiar?”, Asclepio, 73(1): p348. https://doi.org/10.3989/asclepio.2021.14

RESUMEN: Entre 1929 y 1958, los directores del Manicomio General de la Castañeda culparon a las familias de los internos de la sobrepoblación del establecimiento, alegaron que los egresados o no tenían parientes o estos se negaban a recibir a sus deudos. Factores que, a su juicio, impedían reducir la población del nosocomio. En consecuencia, tanto la dirección de la institución como la entidad gubernamental adoptaron una serie de medidas dirigidas a localizar y convencer a los parientes de que asumieran la responsabilidad de la externación de sus enfermos y contribuyeran a su reinserción social. El presente trabajo analiza un conjunto de documentos burocráticos emitidos por la dirección del manicomio y por los responsables de la asistencia pública, relativos al proceso de egreso de los enfermos mentales en su vertiente familiar. Documentos que ponen de manifiesto la complejidad del proceso de externación de los enfermos mentales en un contexto de lucha contra la masificación de esta institución pública y muestran las dificultades, contradicciones y conflictos que se presentaron durante la ejecución de las medidas propuestas por las dependencias implicadas.

PALABRAS CLAVE: Manicomio; Familia; Egresos; Masificación; Asistencia Pública.

\section{PATIENTS'S EGRESS OF THE MANICOMIO GENERAL OF LA CASTAÑEDA (1929-1958), A FAMILY PROBLEM?}

ABSTRACT: From 1929 to 1958, directors of asylum La Castañeda blaming patients' families about overcrowded in the hospital. Directors said that patients had not relatives, or they denied receiving them. This prevented the reduction of the population suffered by the institution. According to this situation, the asylum and public assistance adopted several actions to find and to persuade relatives for they to take their responsibility and help to their family member to social reinsertion. The article examines official documents of the asylum's direction, and public assistance on the egress process of mental illness since family perspective. Those documents expressed the hard process of output on madness in a context of fighting against the overcrowded, and reveal difficulties, contradictions, and conflicts that it presented the execution of actions of mental hospital and Public Assistance.

KEY WORDS: Mental Hospital; Family; Egress; Overcrowded; Public Assistance.

Copyright: (C) 2021 CSIC. Este es un artículo de acceso abierto distribuido bajo los términos de la licencia de uso y distribución Creative Commons Reconocimiento 4.0 Internacional (CC BY 4.0) 


\section{INTRODUCCIÓN}

En 1937 el diario Excélsior publicó una noticia que iniciaba con el provocativo titular: "Libres Quinientos Locos." Si para atrapar al lector no había sido suficiente esta afirmación, el periodista añadió: "Unidos a los que andan en libertad pueden convertir a México en gran manicomio." Este artículo, además de buscar el interés de los lectores, se hacía eco de la incapacidad del Manicomio General de la Castañeda de albergar a más pacientes. Pues, según datos aportados por el director de la institución, el Dr. Alfonso Millán, estaban internadas 2,887 personas en un establecimiento con una capacidad para 1,500 pacientes ${ }^{1}$. El problema no se había originado durante la gestión del Dr. Millán, sino que era una situación que comenzó a manifestarse desde inicios de los años 20 , se volvió preocupante en las siguientes décadas y condicionó el funcionamiento de la Castañeda hasta su cierre en 1968.

El 1 de septiembre de 1910 se inauguró el manicomio y las previsiones acerca del número de pacientes que podían ingresar en él no hacían presagiar las dificultades por la insuficiencia de espacio que tendrían que enfrentar una década después. Había sido construido en 1908, en el ocaso del gobierno de Porfirio Díaz, por obra del gobierno federal y financiado con fondos de la Beneficencia Pública ${ }^{2}$. El proyecto de grandes dimensiones abarcó los antiguos terrenos de una hacienda pulquera para, como señalaba el proyecto, satisfacer una "necesidad social." Pero, sobre todo, con el objeto de paliar el hacinamiento en los antiguos establecimientos coloniales para enfermos mentales, el hospital del Divino Salvador (1700-1910) y San Hipólito (1567-1910), nosocomios que al momento de su clausura duplicaban con creces su capacidad.

La suficiencia de plazas hospitalarias en el recién inaugurado establecimiento duró poco tiempo. Pues, este estaba planeado con una capacidad de 1,330 camas (Valdés, 1995, pp.135-144) y ya, entre 1910 y 1913, el número de internos superaba el millar (Sacristán, 2001, p.93). Los efectos de la revolución mexicana se hicieron notar en el presupuesto destinado al sostenimiento de la institución y en el deterioro de las instalaciones. Aunque, esta coyuntura contuvo el incremento de la población nosocomial, retomó su ritmo de crecimiento a partir de 1920 y se agudizó al final de esta década (Sacristán, 2017, p. 193 (3)).

El presente texto analiza precisamente el proceso de egreso de los enfermos mentales en su vertiente familiar entre 1929 y 1958. Puesto que, en 1929, inició un periodo marcado por la lucha contra la masificación de los directores del manicomio general como res- puesta al aumento excesivo en el número de pacientes. Ya que el sobrecupo afectaba notablemente al funcionamiento y a la gestión de la institución y generaba problemas de convivencia, seguridad, higiene y salubridad. Además, el coste económico para el sustento de una población numerosa era insostenible para las arcas públicas. Situación que provocó tensiones entre la dirección del manicomio y las instancias gubernamentales. Y finaliza en 1958, con el nombramiento del Dr. José Álvarez Amézquita como Secretario de Salubridad y Asistencia, la consiguiente restructuración de la Dirección de Salud Mental que quedó bajo la dirección del Dr. Manuel Velasco Suárez, quien inauguró el progresivo desmantelamiento del hospital de Mixcoac con la fundación, a partir de 1960, de varios establecimientos destinados a la descentralización de la institución de Mixcoac y para el tratamiento de enfermos crónicos y agudos, incluso, el asilo de pacientes que no contaban con soporte familiar.

En este contexto de cruzada institucional contra la sobrepoblación, los directores de la institución culparon a las familias de los internos de la masificación del establecimiento y adujeron que los egresados o no tenían parientes o se negaban a recibirlos. Factores que impedían reducir el sobre cupo en la población del nosocomio. Estos argumentos cundieron en el análisis historiográfico, por ejemplo, Cristina Sacristán (2002, p.72) y Andrés Ríos (2008, p.81; 2009, p.30) concordaron en su análisis y explicaron que, cuando los psiquiatras decidían dar el alta a un interno, se encontraban con que los parientes no querían hacerse cargo de sus deudos. Además, el reglamento interno y la imagen de la institución como asilo obstaculizaban las altas de aquellos que estaban curados, pero no tenían familias o habían sido abandonados. En este mismo tenor, Inés García Canal (2008) presentaba a los parientes como desobligados o resistentes a hacerse cargo de los deudos tras el alta. Sin embargo, estudios recientes señalan que el manicomio fue un lugar de paso, en el que las familias fueron determinantes al solicitar el alta y hacerse cargo de sus enfermos en lugar de abandonarlos y que durante la vida del manicomio el $29.4 \%$ abandonaron el establecimiento por solicitud de un familiar o persona responsable (Ríos, Sacristán, Ordorika, López, 2016, p. 136) (7), (Sacristán, 2017, p.193 (9).

Estas interpretaciones historiográficas acerca del papel de las familias durante el egreso de los pacientes, así como,el intercambio de correspondencia entre los directores del manicomio con los responsables de la asistencia pública hicieron que nos preguntáramos en qué se basaban los médicos para afirmar que el problema de los egresos en el Manicomio General radica- 
ba en las familias. Cuestionamiento que motivó la revisión de los discursos de los procesos de externación, a partir de fuentes documentales de índole burocrática e interinstitucional ${ }^{3}$. Revisión que, además, nos condujo analizar las distintas iniciativas que tomaron las autoridades médicas y de la asistencia pública, entre 1929 y 1958, para facilitar el proceso de egreso de los internos vinculado a las familias en este nosocomio federal.

Iniciativas que según los documentos buscaban localizar e incentivar a los parientes en el ejercicio de su responsabilidad con los egresados para que, de esta manera, contribuyeran a la inserción al medio familiar y social de los ex asilados que estaban curados o en condiciones de vivir fuera de los muros del nosocomio. $\mathrm{Y}$, en este sentido, los análisis y las reflexiones vertidas a lo largo de este artículo pretenden contribuir al conocimiento del proceso de externación e inserción de los enfermos con relación a las familias. Un tema, el del egreso, escasamente trabajado por la historiografía mexicana debido a la dificultad de hallar fuentes que hagan referencia a lo que sucedía fuera de los muros del manicomio. A pesar de estas dificultades, las fuentes públicas que proporcionan los establecimientos hospitalarios y de la asistencia sanitaria del Estado nos han permitido hacer una primera aproximación a la vertiente familiar en la externación de los pacientes. Por todo ello, esperamos que este trabajo enriquezca los enfoques, institucional y social, de la historia de la psiquiatría en México en el siglo XX.

Respecto al tema que nos ocupa, sostenemos que las dependencias implicadas estaban convencidas de que el problema de la masificación de la Castañeda residía en que no se podían localizar a los familiares o estos se resistían a recibirlos, por lo que, hicieron un gran esfuerzo, humano y material, para intentar ubicar y convencer a los parientes de recibir a sus enfermos e involucrarlos en su regreso a la vida en sociedad. Sin embargo, los familiares formaban parte de un complejo proceso de egreso y reinserción social en el que la ausencia de responsables, incluso su participación, puso de manifiesto los intereses encontrados de los directores del manicomio general y de la asistencia pública. Intereses que generaron contradicciones y conflictos en cuanto a los criterios y a la gestión de las salidas; despertó la desconfianza de los funcionarios de la asistencia pública respecto al buen funcionamiento del manicomio; y ocasionó dudas sobre su capacidad de los deudos para atender y vigilar a sus deudos externados. Contradicciones, conflictos y desconfianzas que obstaculizaron la salida de los pacientes curados o en remisión, internos que pasaron a engrosar la población del nosocomio.

\section{EL EGRESO DE LOS PACIENTES DEL MANICOMIO GENERAL}

En medio de la Revolución mexicana, en un ambiente de tensión política generada por el gobierno del régimen militar comandado por el General Victoriano Huerta y en unas nada óptimas condiciones de funcionamiento de la institución, vio la luz el primer reglamento interno del Manicomio General de la Castañeda (1913). En él, el manicomio se definía a sí mismo como un hospital y asilo perteneciente a la Beneficencia Pública, dependencia de la Secretaría de Gobernación y del ejecutivo de la Unión. Instancias públicas encargadas de su sostenimiento y supervisión y en nueve capítulos se recogieron todos aquellos aspectos organizativos que debían regir el eficaz funcionamiento de la institución.

Su artículo 38 contemplaba las siguientes formas de egresar de la Castañeda: Por estar curados de la enfermedad que motivó su entrada; por estar aliviado, o no, siempre que fuera solicitado por los parientes $u$ otras familias que los tuvieran a su cargo; a petición propia cuando no hubieran sido remitidos en calidad de presos y no fueran peligrosos para la seguridad de ellos y de otras personas; y aunque lo fueran cuando el Gobernador del Distrito emitiera la orden. Y su artículo 39 establecía una serie de reglas para hacer efectiva el alta o la salida de los asilados: Los internos, que hubieran ingresado en calidad de libres, serían entregados a la familia o a las personas que lo tuvieran a su cargo. En caso de que esto no fuera posible se les permitiría salir solos, si eran mayores de edad y no eran peligrosos. Si eran menores y no tenían familia se remitiría a alguna otra institución de la Beneficencia Pública ${ }^{4}$.

El siguiente reglamento fue firmado, en 1925, por el director general de la Beneficencia Pública, por el visitador de los hospitales, por los directores y administradores del Hospital General, del Hospital Juárez, del Hospital Morelos y del propio Manicomio General. Tras unas juntas realizadas en la Dirección General de la Beneficencia en las que se estudió y se corrigió el anterior. Aunque como el propio documento afirma, quedó en su mayor parte como el aprobado el 26 de julio de $1913^{5}$. Lo que no sufrió modificación alguna fueron los articulados referidos a las altas, manteniéndose los mismos criterios para otorgar los egresos de los asilados descritos anteriormente. 
Durante décadas los intentos de las distintas instancias de la asistencia pública para que los directores del manicomio hicieran un nuevo reglamento fueron infructuosas. Ni las amenazas de tomar medidas disciplinarias resultaron eficaces. En 1935, el Dr. Alfonso Millán, director del manicomio, escribió al Dr. Priani, secretario general de la Beneficencia Pública, y le pidió que le diera más tiempo para hacer el reglamento del establecimiento. Alegó que las características del hospital eran muy diferentes en lo técnico y lo administrativo a otros nosocomios y recalcó que la ausencia de una ley de enfermos mentales en el Distrito Federal complicaba la realización de un documento que debería poder basarse en un ordenamiento jurídico de carácter general que le diera mayor fuerza legal ${ }^{6}$. En este sentido, las preocupaciones del Dr. Millán se basaban en que el reglamento interno que estaba en vigor y regulaba su práctica no blindaba su práctica profesional ni dentro ni fuera del manicomio.

Por otra parte, entre 1929 y 1944, la situación política y social del país cambió notablemente y la salud mental tomó un lugar destacado en las políticas sanitarias de los gobiernos posrevolucionarios. Prueba de ello fue la creación del Servicio de Higiene Mental (1936), la Liga Mexicana de Higiene Mental (1939) y el Instituto de Higiene Mental (1946), organizaciones dirigidas a la prevención de las enfermedades mentales (Ríos, 2010, p.1308) y que formaron parte de lo que Beatriz Urías ha denominado "programa de ingeniería social", donde la higiene mental tenía el objetivo de regenerar física y moralmente a la población y perseguía erradicar la herencia degenerativa, origen de los padecimientos mentales (Urías, 2004) y que además coincidió con el severo incremento de la población nosocomial. Misma que se mantuvo estable, aunque con sobrecupo, a partir de 1944 (Ríos, Sacristán, Ordorika, López, 2016, p.136 (4)).

Los cambios constantes en la dirección del manicomio, las rotaciones de personal y la falta de constancia en la organización administrativa parecían imposibilitar que se aprobara un nuevo reglamento interno que contemplara aquellos aspectos que se modificaron en la oficina de admisión en 1944. La ausencia de un reglamento, sin embargo, no impidió que se implementaran otros proyectos encaminados a la mejora y sistematización de las labores de los distintos departamentos que componían la Castañeda. En relación con esta ausencia, en 1945 el Dr. Leopoldo Salazar Viniegra escribió: "esta circunstancia parece indicar que la necesidad de dicho reglamento no se ha hecho sentir en lo absoluto hace muchos años"7. Pues, el manicomio había funcionado con la inercia de la práctica de los médicos y de los trabajadores del nosocomio, con acciones que intentaban dar respuesta puntual a los problemas que se iban suscitando y muchas veces, motivadas por las exigencias de la Secretaría de Asistencia Pública.

Esta política de respuestas puntuales no fue diferente en el caso de los egresos, ya que estos funcionaron gracias a la organización del departamento de admisiones y a su práctica cotidiana y con disposiciones que se aprobaban para solventar los muchos problemas que se generaban por la masificación del establecimiento. Por ejemplo, en 1956, los motivos de alta recogidos en un informe de labores técnicas y administrativas firmado por el director del establecimiento, el Dr. José Chávez Almazán, se habían complejizado. Los internos podían ser causa de baja por las siguientes razones: por curación con reservas o remisión; por mejoría (voluntaria o por solicitud familiar); por pase a otros establecimientos de la asistencia pública; por fugas, por defunción y por permiso temporal ${ }^{8}$. Disposición normativa de índole casuística que pone de manifiesto, por una parte, la infinidad de situaciones que estaban presentando al momento del egreso; y, por otra, que en los egresos en los que estaba involucrada la familia había un proceso de negociación que con frecuencia generaba tensiones entre los familiares y los médicos y de éstos últimos con la asistencia pública.

\section{El egreso, ¿Un problema familiar?}

Si tomamos en cuenta las distintas formas en las que los pacientes podían abandonar la Castañeda según los reglamentos de 1913 y 1925 y las distintas disposiciones que se aprobaron durante el periodo de estudio en la que los familiares estaban involucrados y tomamos los datos del estudio de Andrés Ríos, Cristina Sacristán, Teresa Ordorika y Ximena López (2016, p.136) basado en la demografía psiquiátrica, ${ }^{9}$ entre 1910 y 1968 , el $29.38 \%$ de los pacientes salieron del nosocomio por solicitud familiar, el $13.8 \%$ lo hicieron por curación, remisión o eran aptos para vivir en familia. Estos porcentajes resultan reveladores de la participación de los parientes en el momento de egreso. Pues, el $43.18 \%$ habrían salido porque así lo habría querido sus deudos o lo habrían hecho acompañados de una persona responsable. Porcentaje que podría verse incrementado si tomamos en cuenta que el $12.3 \%$ de los internos que salieron de un permiso, solicitado por un familiar o responsable, no regresaron al manicomio.

Sin embargo, otros documentos apuntan a que la realidad del egreso era bastante diferente. Por ejemplo, unos datos del departamento de Terapia Social 
enviados en 1940 por la trabajadora social Guillermina Morales, con una lista de enfermos que podía regresar a sus hogares ${ }^{10}$. De 97 internos, 25 carecían de responsables o de personas que pudieran garantizar su vida en el medio familiar, ${ }^{11}$ lo que supone que en un $25.77 \%$ el manicomio tuvo que tomar la decisión de qué hacer con los internos que podían salir, pero no tenían soporte familiar. De esos 25 internos, algunos debieron irse solos y otros como ocurrió durante décadas fueron trasladados a otros establecimientos dependientes de la Asistencia Pública ${ }^{12}$ como el hospital de enfermos crónicos de Tepexpan ${ }^{13}$. Y a partir de 1945 a las granjas hospitales. $\mathrm{O}$ también podían ser adjudicados a instituciones privadas como la Sociedad de Beneficencia Española ${ }^{14}$. Instituciones públicas y privadas que hicieron las veces de entorno familiar, mientras los enfermos podían reinsertarse en la sociedad.

Este $25.77 \%$ parece coincidir con lo que ya apuntó, en 1932, el encargado de admisiones cuando envió dos listas con los internos que según su criterio no merecían la estancia en el establecimiento e informó que la mitad de los enfermos consignados en esas listas habían sido dados de alta. Y de la otra mitad, algunos estaban esperando a sus familiares y otros no tenían ${ }^{15}$. En datos como los aportados por el responsable de admisiones son en los que se basaban los discursos de los directores del manicomio general cuando afirmaban que el problema del egreso era familiar. Sirva de ejemplo, un escrito del Dr. Manuel Guevara Oropeza quien expresó que el problema de los egresos de los enfermos residía en que los familiares se rehusaban terminantemente a recibirlos en sus domicilios, habían desaparecido o no encontraban a ninguna persona que pudiera acogerlos ${ }^{16}$.

En cuanto a la renuencia de los deudos de recibir a sus enfermos egresados, en un documento del 29 de marzo de 1933, el jefe del departamento de admisiones envió la cifra de 108 enfermos que fueron dados de alta. Noventa fueron recogidos por sus familiares y dieciocho no los quisieron albergar en sus domicilios ${ }^{17}$. Lo que supuso que el $16.66 \%$ o 18 familias ponían a las autoridades del manicomio en el brete de decidir si los dejaban marchar solos o la institución hacía el esfuerzo de contactar nuevamente a los deudos y convencerlos de aceptar su responsabilidad ${ }^{18}$. Ante esta complicación, los responsables del nosocomio y de la asistencia pública contemplaron qué podía pasar si los familiares no acudían a los llamados para ir a recoger a sus parientes.

Respecto a los problemas para localizar a los parientes, ocurría con frecuencia que la persona que figuraba en los libros de registro y en el expediente clínico como responsable legal no se encontraba en el domicilio de contacto. Suceso que se llegó a imputar a la mala fe de los deudos, ${ }^{19}$ pero que podía haber ocurrido por diversas causas como el fallecimiento de la persona que se hacía cargo del enfermo ${ }^{20}$ o la pérdida del vínculo familiar al momento del ingreso (Rodríguez Cabo, 1944, Sacristán, 2017, p. 193(4)). Incluso, pudo producirse la remisión de pacientes por parte de las autoridades sin que se conocieran sus datos personales o de filiación. Este último asunto resultaba espinoso tanto para los médicos como para los funcionarios de la Beneficencia Pública, pues, era frecuente que ingresaran enfermos que carecían de familia porque habían sido internados sin tenerla y entonces no había datos de ellas; o que, al momento de haber sido enviados por las autoridades, los parientes no estaban enterados de su destino. Como resultado era bastante habitual que el manicomio recibiera enfermos enviados por las delegaciones y por los hospitales adscritos a la Secretaría de Salud y que estos no enviaran los requisitos legales indispensables, ni datos suficientes para la identificación del interno y de sus familiares ${ }^{21}$. El desconocimiento de estos datos llevó en 1933 al Dr. Salvador M. Navarro, jefe del departamento médico de la Beneficencia Pública, a enviar un oficio al Inspector de Policía en el que pedía su ayuda ante la imposibilidad de localizar a las familias de cuatro enfermas ${ }^{22}$.

De todas formas, la incapacidad de encontrar a las familias y que los internos salieran solos no tenía por qué haber sido una fuente de tensiones entre el manicomio general y la asistencia pública, si se toma en cuenta que los reglamentos de 1913 y de 1925 habían sido aprobados por ambas instancias y eran claros. Contemplaban la posibilidad de que los internos salieran solos si no había una persona responsable. Sin embargo, tanto la naturaleza asilar del nosocomio aducida por el jefe del Departamento de Asistencia ${ }^{23}$ como el temor de que los enfermos externados fueran peligrosos para ellos mismos o para los demás producía contradicciones y conflictos en la aplicación de las normas de egreso. Este fue el motivo por el que, en 1933, el Dr. Salvador M. Navarro pidió su opinión sobre el proceso de salida de los enfermos mentales y propuso que la policía cooperara con la vigilancia de los enfermos y enfermas externados y así evitar trastornos en la seguridad pública. Este escrito, según explicó el responsable de la beneficencia, estaba motivado por la situación del establecimiento y lo "angustioso" del cupo de enfermos ${ }^{24}$.

Desconocemos si se obtuvo la ayuda solicitada a la policía para la localización y vigilancia de los ex asi- 
lados del Manicomio General, pero, ante situaciones como estas, el manicomio y la asistencia pública tomaron distintas iniciativas como la reforma de la oficina de admisiones, la implementación de un servicio con trabajadoras sociales que se encargaran de localizar o convencer a las familias y así facilitar la salida de los internos. Además, se crearon mecanismos para apoyar económicamente a los pacientes que trabajaban en el hospital y fueran dados de alta. Se crearon las clínicas externas, primero al interior del manicomio, para dar seguimiento a los pacientes.

Sin embargo, cualquier esfuerzo de la institución parecía resultar ineficaz si no existía una red de familiares, amigos o patrones que acogieran y acompañaran al ex asilado en el camino de su inserción social. Pues, en ausencia de personas que se quisieran hacer responsables o ante la carencia de familiares, el destino de los enfermos estaba en manos de un manicomio que no tenía espacio y al que le escaseaban los recursos o la institución se veía en la necesidad de asumir el riesgo de dejarlos salir sin supervisión familiar.

\section{LOS ESFUERZOS DE LAS INSTITUCIONES PARA MEJORAR EL PROCESO DE EGRESO}

En 1929, el director Dr. Samuel Ramírez Moreno implementó la terapia ocupacional para los enfermos mentales en un intento de mejorar el tratamiento de los enfermos crónicos y de facilitar un medio de vida a aquellos que pudieran ser dados de alta ${ }^{25}$. Tres años más tarde, en 1932, comenzó una reforma médico-administrativa que se materializó en el pabellón central. La labor de Ramírez Moreno fue continuada por el Dr. Manuel Guevara Oropeza quien reorganizó la oficina de admisión. (Sacristán, 2017a). Al mismo tiempo, los médicos de la Castañeda consolidaron terapias basadas en el trabajo, el deporte o el arte (Sacristán, 2005a, 2005b, 2008) en un esfuerzo por curar los padecimientos y paliar la cronicidad de la enfermedad mental ${ }^{26}$. Es más, en 1941, se comenzó un proyecto para la creación de granjas dirigida a la recuperación de enfermos

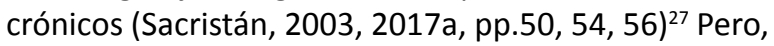
ni la inauguración de esta granja ni la creciente medicalización resultó suficiente para aumentar de forma considerable el número de altas y disminuir la población hospitalaria.

Desde 1943, la promoción de la salud mental quedó en manos del Departamento de Neuropsiquiatría en higiene mental de la Secretaría de Salubridad y Asistencia (1943-1968). Por su parte, el Manicomio General estaba aplicando las nuevas terapias de choque y las novedosas tendencias farmacológicas y tomó varias medidas para mejorar el funcionamiento de la institución. Y en medio del cambio en la asistencia pública, en 1944, el comisario de admisiones Gustavo G. Abascal remitió un "Ante Proyecto de Reglamento y Funcionamiento de la admisión del Manicomio General" con el objeto de llevar un mayor control sobre los ingresos y los egresos de pacientes. En el documento expuso que la oficina de admisión, o comisaría, era la encargada de externar y controlar el movimiento de los internos. Pero las altas debían ser solicitadas a través de la dirección del manicomio ${ }^{28}$. Esta necesidad de que los egresos fueran ratificados por el director del manicomio puso de manifiesto que, internamente, el funcionamiento del nosocomio era deficiente y que se habían producido altas que no estaban justificadas.

Conforme a este proyecto, los encargados de los pabellones hacían listas con los enfermos en remisión en las que aparecían, además, de los nombres, si éstos tenían familia, de dónde eran y si podían abandonar solos el establecimiento ${ }^{29}$. Pues la importancia de localizar a los familiares de los internos estaba en que ellos eran los responsables legales y morales de los ex asilados, pero en caso de no tenerlos, de no encontrarlos o de no convencerlos, los directores del nosocomio y los funcionarios de la asistencia pública se veían en la difícil decisión de permitir que los enfermos curados o en remisión pudieran marcharse solos. Esta normativa duró casi una década y como veremos más adelante fue fuente de contradicciones y conflictos entre el personal director del manicomio y de la asistencia.

Además, el proyecto de reglamento para el funcionamiento de la oficina de admisión especificó que cuando un enfermo estuviera dado de alta por remisión, la oficina tendría la obligación de comunicar por escrito el estado del enfermo a sus familiares para que se presentaran a recogerlo. Si en veinte días no había recibido respuesta a los avisos girados, conforme con lo establecido por el reglamento interno, de 1925, se dejaba salir solo al enfermo, recayendo cualquier responsabilidad en los familiares. Pero también estipulaba que si habían pasado dos meses de haber sido dados de alta y los familiares o responsables habían sido avisados, pero no se habían presentado a recogerlos, se les proveería de pasajes al centro de la ciudad, dejándolos en libertad ${ }^{30}$.

En 1947, Leopoldo Salazar Viniegra, director del nosocomio, reestructuró nuevamente el espacio y el organigrama del nosocomio y el pabellón central comenzó a funcionar como centro de consultas externas y para el servicio abierto (Sacristán, 2017a, p.64). En este pabellón también ejercían su labor las trabaja- 
doras sociales ${ }^{31}$ aunque su servicio como tal, se había instaurado en 1944, gracias a la iniciativa de la Dra. Mathilde Rodríguez $\mathrm{Cabo}^{32}$ con el objeto era facilitar el egreso de los pacientes y procurar que éstos no se quedaran desprovistos de protección y asistencia tras su salida del establecimiento ${ }^{33}$. En las funciones de las trabajadoras sociales parecían coincidir tanto el director del manicomio, el Dr. Samuel Ramírez como el director general de asistencia del departamento de atención neuropsiquiátrica el Dr. Ricardo Labardini.

En este momento, el Dr. Labardini exhortó al Dr. Ramírez a que antes de dar de alta a un enfermo se hiciese una investigación de su estado social con el fin de conocer la situación económica de su familia, siendo las encargadas de tal misión las trabajadoras sociales adscritas al establecimiento ${ }^{34}$. Para hacer ese estudio, la trabajadora social encargada del pabellón debía localizar personalmente a los parientes, haciéndoles "sentir la necesidad de que fueran por su enfermo", pues podía suceder que los responsables se hubieran cambiado de domicilio y no hubieran avisado a la oficina de admisiones. Tal y como lo presentó Labardini da la sensación de que el estudio era un pretexto para convencer a las familias de que se ocuparan de su enfermo próximo a egresar, aunque las trabajadoras sociales estaban encargadas, también, de hacer los trámites necesarios para que los deudos lo ayudaran a adaptarse al medio social ${ }^{35}$.

En la práctica, la función de las trabajadoras sociales se dirigió principalmente a la búsqueda de los deudos, más que a la evaluación de la capacidad familiar para la inserción del enfermo en su entorno doméstico y social ${ }^{36}$. Labor en la que también estaban involucrados los jefes de los pabellones. Prueba de ello fue un escrito de 1954 en la que el comisario del Manicomio General instó al director del establecimiento, el Dr. Francisco Núñez, y al jefe del pabellón de agitados, el Dr. Juan Peón del Valle, a avisar sistemáticamente a los familiares para que recogieran a sus enfermos, concediendo un plazo de una semana para que se cumpliera con esta petición. En este sentido, y de acuerdo con lo apuntado por Cristina Sacristán, los esfuerzos por constituir un servicio social que se encargara de la "vigilancia" y una "acción social continuada" se toparon, con frecuencia, con la incapacidad de seguir en contacto con las familias una vez que los enfermos habían sido dados de alta. (Sacristán, 2017, p.193) ${ }^{37}$.

\section{Del consultorio central a las consultas externas ${ }^{38}$}

El servicio de consulta externa al que hacía referencia el anteproyecto de 1944 se había prestado al interior del Manicomio General desde 1933 cuando se había inaugurado un consultorio central, encaminado a proporcionar una atención más profesionalizada a los enfermos y que además intervenía en el manejo de los ingresos y egresos de los pacientes.

Tanto en el consultorio central como en las consultas externas, los médicos comisionados determinaban quiénes no necesitaban hospitalización y quiénes precisaban ser atendidos en el manicomio. Incluso, proporcionaban el certificado de admisión a los que fueran a ser internados en la Castañeda y no contaban con él (Sacristán, 2010, p.478). Esta criba inicial facilitaba la disminución del número de ingresos, pero en opinión de la asistencia pública no resultaba tan efectiva en los egresos.

Por este motivo, dos meses después de creado el consultorio central, en junio de 1933, la junta directiva de la Beneficencia Pública pidió explicaciones al director del Manicomio General sobre las causas por las que los enfermos que durante su remisión estaban en condiciones de vivir en el medio social, yendo a consulta, seguían internados en el establecimiento. Pues, según los datos de la instancia benéfica, la existencia del consultorio para enfermos de psiquiatría no había repercutido en la despoblación de los enfermos internados ${ }^{39}$. Esto despertó la desconfianza de la Beneficencia Pública que empezó a cuestionarse la manera en la que el manicomio estaba usando el consultorio y la forma en la que se estaba llevando a cabo la política de egresos. Tanto era su descontento con la gestión del nosocomio, que iban a mandar a dos facultativos a hacer un análisis de los casos clínicos de los enfermos que posiblemente estaban en condiciones de ser externados y, así, comprobar si se estaba actuando con diligencia en la concesión de altas.

En respuesta, el director en turno, Dr. Guevara Oropeza, ofreció su total colaboración a los facultativos de la Beneficencia Pública que iban a llegar a la Castañeda, no sin mostrar cierto malestar con lo que debió percibir como una intrusión y cuestionamiento en su dirección del nosocomio. En su respuesta, defendió la calidad y buena voluntad de los médicos del servicio y se escudó en que los familiares se rehusaban a admitir a los egresados en sus domicilios o bien estos habían desaparecido. En su descargo explicó que se estaban dando de alta a enfermos que no estaban curados totalmente, solo mejorados y en condiciones de vivir en el medio doméstico y advirtió que cuando salían sin apoyo familiar eran reintegrados por las autoridades judiciales al muy poco tiempo de ser externados. Asimismo, apuntó que había enfermos que hacían un trabajo útil en el manicomio, pero su peligrosidad o los 
trastornos mentales que sufrían les impedían vivir en familia, lo que obligaba al establecimiento a conservarlos como asilados ${ }^{40}$.

Tras recibir este informe, el Dr. Salvador Navarro, del Departamento Médico de la Beneficencia Pública, se mostró comprensivo con lo expuesto por el director Guevara Oropeza y alabó la labor del manicomio en cuanto a la terapia ocupacional, aunque no perdió la oportunidad de exponer un fenómeno que le causaba desconfianza. Pues, según sus datos, desde que había empezado a funcionar el consultorio en el manicomio general habían disminuido los ingresos, pero también las altas y quería que le dieran explicaciones acerca de los egresos ${ }^{41}$. Finalmente, Guevara Oropeza se comprometió a estudiar las causas de esta anomalía.

Los motivos de la reducción de los ingresos se explican simplemente con que esta dependencia sirvió de filtro para los nuevos ingresos, ya que estaba destinada a evaluar a los pre pacientes que necesitaban ser internados y diferenciarlos de aquellos que podían vivir con un tratamiento ambulatorio o que simplemente no sufrían enfermedad mental alguna (Sacristán, 2017a, p.45). En cuanto a los egresos, estos no dependían directamente de que esta dependencia hiciera bien su labor sino, como apuntó Guevara Oropeza, de que los internos tuvieran familiares y de que estos estuvieran dispuestos a recibirlos, vigilarlos y hacerse responsables de cualquier acción que los ex asilados cometieran, sin que se vieran comprometido ni el manicomio ni la asistencia pública. Además de evitar la alarma social que se podía originar en caso de que la prensa se hiciera eco de la salida de muchos "locos" sin respaldo familiar" ${ }^{42}$. Por eso, Guevara Oropeza alegaba que una vez que egresaran con sus deudos, el consultorio podía cumplir con su labor de hacer un seguimiento a la salud de los ex pacientes.

Las explicaciones del director no impidieron que la Beneficencia Pública comisionara a los doctores Carlos García Garza y Carlos Véjar para supervisar el funcionamiento de la clínica y del manicomio. Estos mandaron un primer informe en el que destacaron las facilidades que Guevara Oropeza les había proporcionado para hacer su evaluación y explicaron que habían mantenido entrevistas con los médicos de los pabellones y con algunos pacientes que estaban en franca mejoría y en condiciones de vivir en el medio familiar. Como eran muchos, estos médicos solicitaron una lista para el plan de trabajo. Los obstáculos que detectaron fue la carencia de un servicio social que pudiera vigilar y cuidar posteriormente a los ex asilados que llegaban al seno social o familiar después de ser dados de alta. Además, consideraron que muchos internos parecían que podían salir por su capacidad para trabajar en el manicomio, pero la carencia de familiares, de medios económicos, los conflictos morales y la inadaptación social podían despertar sus síntomas y convertirse en delincuentes o viciosos. Poniéndose en peligro ellos y a la sociedad. Lo cual traería serias responsabilidades para los médicos que habían autorizado la externación ${ }^{43}$.

Se tomaron en cuenta algunas de las recomendaciones sugeridas por los doctores García Garza y Véjar, pues en 1934, cuando se reestructuraron todos los consultorios de la capital, el Manicomio General de la Castañeda pudo establecer su primera consulta externa fuera de la institución: El que pasó a denominarse Consultorio número 1 y que se encontraba en el Hospital General. En ellos, dos médicos pasaban consulta y extendían los certificados para aquellos enfermos que necesitaban ingresar en el manicomio y daban seguimiento a los pacientes dados de alta (Sacristán, 2017a, pp.52-54, 55.) Una década después, en 1944, gracias a las reformas propuestas por el director del establecimiento, este servicio de consultas externas empezó a depender de la oficina de admisiones y solo los ex asilados que ya estaban en el medio familiar podían utilizarlo en los días y horas señaladas y siempre de acuerdo con la situación económica y el estudio que hubieran hecho las trabajadoras sociales ${ }^{44}$.

Asimismo, el anteproyecto de 1944 contemplaba que los pacientes no podían reingresar al manicomio salvo que el médico de la consulta externa así lo ordenara y lo hicieran siempre con la anuencia de los familiares; pero en caso de urgencia, el médico debía realizar la documentación pertinente sin contar con los deudos ${ }^{45}$. Además, en este momento, las salidas de asilados podían producirse de dos formas: por alta y por permiso, pero para efectuar cualquiera de las dos, el responsable legal debía presentarse en la oficina de admisión y firmar un formulario, al menos, con 72 horas de anticipación a la fecha de salida. Especificando en la solicitud de permiso el tiempo que la familia deseaba que el asilado permaneciera fuera del establecimiento. Una vez cumplido el plazo solicitado y siempre que no se hubiera pedido prórroga al director, el enfermo sería dado de alta 10 días después de esperarlo. Para las fugas, el plazo se ampliaba 90 días $^{46}$.

En 1948, los enfermos que eran dados de alta también podían dirigirse a un consultorio situado en el Hospital Juárez o acudir al centro de adiestramiento y dispensario central antivenéreo situado en la calle de Tolsá. Estos espacios, al igual que el consultorio del pabellón central y el número 1 del Hospital General, estaban destinados a la vigilancia de los tratamientos de 
los egresados. Pasaban consulta diariamente de 9 a 11 de la mañana y los usuarios debían aportar una síntesis de su historia clínica, misma que debía ser entregada por el manicomio como parte de los trámites de alta ${ }^{47}$. Mediante las consultas, los enfermos egresados pudieron seguir siendo atendidos fuera del establecimiento y recibir atención terapéutica y "vigilancia social." 48 Al menos en teoría, porque, además de no ser muy numerosos, las condiciones económicas, el lugar de residencia de las familias y la falta de disposición en los ex asilados para seguir recibiendo tratamiento, dificultaron el funcionamiento eficaz de estos dispensarios.

En 1950, el director de la asistencia médica, el Dr. Álvarez Amézquita, informó de la creación de otro dispensario neuropsiquiátrico en Tacubaya donde se podían mandar a los enfermos que salieran de alta con una copia de la historia clínica, el diagnóstico y la clase de atención que requería, si era terapéutica o de vigilancia social. Para sistematizar la información solicitada y ante la falta de personal, el director del manicomio el Dr. Núñez Chávez sugirió que se hiciera un "machote" informativo que pudiera ser fácilmente rellenado por los médicos de cada pabellón ${ }^{49}$. Este detalle burocrático revela las dificultades que tenían los médicos y el personal administrativo de la Castañeda para gestionar la cantidad de pacientes que eran dados de alta y llevar un seguimiento personalizado de la evolución de cada uno de los enfermos o de las necesidades que podían tener una vez se abandonaba el manicomio. Y en este sentido, tanto la labor de las clínicas como de las trabajadoras sociales eran insuficientes para atender a la cantidad ingente de egresados del Manicomio General de la Castañeda.

En 1958 con el nombramiento de José Álvarez Amézquita, como Secretario de Salubridad y Asistencia, y la consiguiente restructuración de la Dirección de Salud Mental, principió el progresivo desmantelamiento del hospital de Mixcoac, asunto que oficialmente se decidió en 1965 y que finalizó con la clausura del establecimiento en $1968^{50}$ (Vicencio, 2017, pp. 32, 48-49).

\section{TENSIONES Y CONTRADICCIONES EN EL PROCESO DE EXTERNACIÓN DE PACIENTES}

Como mencionamos anteriormente, los reglamentos internos de 1913 y 1925 contemplaban que los enfermos dados de alta que no tuvieran familiares podían salir solos. Y en consonancia, entre 1935 y 1936, cuando la práctica de dar de alta únicamente a aquellos enfermos curados o en remisión que fueran recogidos por sus familiares no se podía cumplir, el manicomio tomaba la alternativa de conceder el alta y dejarlos salir solos. El criterio de quién abandonaba el manicomio sin respaldo familiar dependía de que la persona no fuera problemática y que, por su estado mental, pudiera insertarse sin causar alarma social fuera del nosocomio. Un ejemplo de un grupo que cumplió con estos requisitos fueron las mujeres epilépticas que según los médicos se encontraban en condiciones de poder vivir en el medio social porque tenían crisis poco frecuentes y eran dóciles ${ }^{51}$. Es más, para facilitar su salida, en 1935, el encargado del pabellón de epilépticas sugirió que se permitiera a las mujeres que estaban en condición de vivir fuera del manicomio, salieran acompañadas con una empleada del establecimiento ${ }^{52}$. Desconocemos si esta medida fue llevada a cabo finalmente y algunos ex asilados salieron acompañados por personal del manicomio, pero se sabe que, en 1936, varios internos del pabellón de epilépticos que tenían familiares, pero no fueron a recogerlos, fueron dados de alta y se marcharon solos ${ }^{53}$.

La Junta de la Beneficencia Pública, por su parte, tomaba una dualidad respecto a que los enfermos externados abandonaran el establecimiento de esta forma. En 1933, el jefe del departamento de esta dependencia gubernamental expuso que se estaban dando de alta a personas que simplemente habían mejorado y aunque los médicos decían que estaban en condiciones de vivir en el medio familiar, por ellos mismos no eran capaces de hacer frente a una vida fuera del nosocomio. Por lo que eran remitidos por las autoridades al poco tiempo. $Y$ advirtió que aquellos que desempeñaban algún trabajo útil podría parecer que estaban en posibilidad de salir, pero en algunos casos, por su peligrosidad, no estaban en condiciones de adaptarse y debían conservarlos entre los muros del hospital ${ }^{54}$.

Sin embargo, en 1935, los funcionarios de la beneficencia pública insistieron en que hicieran efectiva la salida de tres enfermos, aunque sus familiares no hubieran acudido a su llamado ${ }^{55}$. Ante la dualidad, los médicos de los pabellones del Manicomio General se sentían presionados por el director en turno, que a su vez estaba obligado por las exigencias de la asistencia pública en materia de externación de pacientes. Esto hizo que se sistematizaran los criterios de alta, pero se aplicaran de forma flexible y casuística. En 1938, los enfermos podían salir por estar en completa remisión o cuando su estado les permitiera volver a su vida social con el tratamiento adecuado siempre que no fueran peligrosos ${ }^{56}$. De esta manera, en los años 30, la máxima preocupación de la asistencia pública estaba enfocada a que no salieran del manicomio personas que pudieran perturbar la paz social.

A diferencia de los años 30, en los años 40, a los responsables de la Secretaría de Salubridad y Asistencia, 
aparentemente, les preocupaba más la "reintegración familiar y social" de los ex asilados ${ }^{57}$. Por este motivo, en 1942, se detalló que la remisión de este tipo de pacientes implicaba tres niveles diferentes: completa, apreciable y discreta. Y los criterios que definían las posibilidades de adaptación de los internos se analizaban en función de tres campos: el familiar, el social y el laboral. Así, algunos enfermos podían estar en condiciones de convivir en el entorno doméstico, pero según criterio facultativo no ser aptos para relacionarse en la sociedad o para trabajar. Y otros estaban capacitados para laborar, pero no iban a poder adaptarse al ámbito familiar ${ }^{58}$. Esta definición de criterios no evitó que, en 1943, el Dr. Clemente Robles, responsable del departamento de asistencia médica, culpara al director del manicomio de las quejas que llegaron a la dependencia pública, por haber dejado salir a ciertos enfermos por remisión de la enfermedad y que "a la postre" habían resultado parcialmente curados e incapaces de ganarse la vida. Y exhortó al director a que enviase a las trabajadoras sociales adscritas al establecimiento a conocer a los familiares y ver si podían hacerse cargo de sus necesidades ${ }^{59}$.

A lo que Manuel Guevara Oropeza contestó que con frecuencia eran dados de alta enfermos que tenían familia y le dio a entender que, aunque se hiciese una investigación amplia de cada caso, era imposible retener a los internos cuando ellos estaban en condiciones de salir. Además, esa medida empeoraría la situación de aglomeración en el establecimiento. Y le recordó que, desde tiempos de la Beneficencia Pública, las disposiciones de las autoridades fueron encaminadas a externar, de la manera que fuera, al mayor número de internos. Le informó, también, que se hacía el estudio social en aquellos casos en los que los familiares no fueran a recoger a sus enfermos. $Y$ le sugirió que le diera una solución para aquellos internos curados o en remisión que carecían de familia y que estaban ocupando un sitio que era necesario para otros enfermos ${ }^{60}$.

Clemente Robles no tuvo en cuenta las explicaciones de Guevara Oropeza y le exhortó a que se abstuviese de dar de alta a los enfermos que no tuvieran familiares, justificando esa decisión en la condición asilar del Manicomio General ${ }^{61}$. Guevara no quedó conforme con esa disposición y expuso que eran enfermos que ya estaban curados, a los que no se les podía privar de su libertad, pero que al no tener familia se les condenaba a seguir como internos del establecimiento indefinidamente ${ }^{62}$. A lo que Robles indicó que para esos casos se dirigiera al Departamento de
Asistencia Diversa de la Dirección General de Asistencia para que ellos realizaran los trámites oportunos ${ }^{63}$.

Sin embargo, un año después, la misma entidad benéfica sugirió que se concedieran todas las solicitudes de alta cuando los pacientes hubieran recuperado su salud, pero se obligaba a los deudos a que presentaran un documento en que se comprometieran a hacerse cargo del externado ${ }^{64}$. Pues, querían que salieran la mayor cantidad de enfermos por el coste económico que suponía el sostenimiento de los internos del Manicomio General, pero cuando arreciaban las críticas en los periódicos (a raíz de los problemas de seguridad pública que provocaban los ex asilados del manicomio) se limitaban los egresos.

Por otra parte, el desamparo familiar, en algunos casos, fue subsanado por la propia institución para dementes. Misma que con frecuencia utilizó a los pacientes en remisión como mano de obra para las labores agrícolas y los talleres de ergoterapia (Sacristán, 2005, p.677-688). Ya que, en los años 30 y 40, el trabajo era visto por los médicos como un medio para aliviarse de la enfermedad mental y una forma de adaptar a los enfermos a sus trabajos primitivos, siendo su experiencia en los talleres, además, una forma de ganarse la vida que podía aplicarse también fuera del establecimiento. A pesar de su importancia terapéutica y adaptativa, entre 1935 y 1938, los talleres no estaban preparados para cumplir con el servicio social de reinsertar a los enfermos a la sociedad. Además, planeaba la sombra de la sospecha de que esta herramienta terapéutica obedecía al interés económico del manicomio y de la asistencia pública. Pues, durante estos años se estaba discutiendo la forma en la que debería ser remunerado el trabajo de los internos para que cumpliera con estas funciones y no se convirtiera en una forma de explotación ${ }^{65}$.

Por tanto, las tensiones entre los responsables del manicomio y de la asistencia pública con motivo de la externación fueron constantes hasta la clausura de la Castañeda. Los médicos podían afirmar que los ex asilados estaban curados, los parientes podían estar dispuestos a convivir con ellos y se contaba con las clínicas externas para los tratamientos extramuros, pero nada podía asegurar que los ex asilados no cometieran acciones peligrosas para ellos mismos y para los demás. Esto generaba el recelo de los médicos de la Castañeda y de los juristas sobre las posibles responsabilidades de los médicos en caso de problemas de seguridad pública, preocupación que era compartida con los funcionarios del gobierno. 


\section{LAS FAMILIAS Y "UN DERECHO QUE NO PODÍAN MANEJAR POR SI MISMOS"}

Las acusaciones de los médicos sobre la falta de implicación de los parientes al momento del egreso, daba la sensación de que todas las familias de los internos de la Castañeda no se preocupaban por sus deudos. Empero, las solicitudes de egreso de los parientes ponen en duda esta imagen. Ante estas peticiones, los directores del Manicomio General y los jefes de la Asistencia Pública tomaron posiciones contradictorias respecto a la concesión de las altas, sobre todo en casos de deudos que estaban en remisión, pero no curados, pues, temían que las consecuencias de una salida temprana terminaran afectando a la institución manicomial.

El proceso de egreso discurría de la siguiente forma: una vez que el director recibía el ocurso, y antes de emitir un juicio, pedía informes a los médicos y practicantes sobre los progresos del enfermo. Los facultativos en turno valoraban si era viable la salida y la institución podía negarse a ejecutarla. Ya que, la reintegración de los enfermos mentales, según lo entendían los médicos y funcionarios, dependía de la capacidad del egresado para vivir con sus parientes, trabajar y relacionarse con los demás. Estas cualidades debían ser evaluadas previamente por los facultativos de la institución, tomando en cuenta el tipo de enfermedad y el grado de remisión. Este modelo obviaba la necesaria participación de los familiares, de los amigos y de los potenciales empleadores en este proceso de reinserción. Pues se daban casos, con demasiada frecuencia, en la que salían enfermos considerados como aptos y regresaban poco tiempo después a petición de los mismos familiares, de los patrones o de las autoridades que poco antes habían solicitado un alta o permiso ${ }^{66}$.

Entre 1920 y 1944, aumentaron los pacientes que no regresaron del permiso (Ríos, 2010, p.1310). Estas salidas temporales se convirtieron en una estrategia para que los internos se incorporaran a la vida familiar (Ríos, Sacristán, Ordorika, López, 2016, p.136 (7)) y también supusieron periodos de prueba que podían aplicar los facultativos antes de que se diera un alta definitiva. Incluso, los parientes usaban estas salidas, que a veces duraban unas horas o unos pocos días, para llevar a sus parientes a celebraciones familiares, de paseo o de vacaciones. La concesión de permisos, como ocurría también con las altas, se había convertido en un acto de negociación de los familiares con los médicos, puesto que el manicomio necesitaba dar de alta al mayor número de pacientes sin poner en peligro su reputación, pero las familias también querían imponer su voluntad y no tomaban en cuenta las recomendaciones de los facultativos.

Por este motivo, esta práctica, un tanto irregular, intentó ser codificada en 1948 por el director del Manicomio, el Dr. Francisco Núñez Chávez. En ese momento se estableció que cuando un médico negara un permiso, por no estar en condiciones de salir, y los familiares se obcecaran en su petición, contaban con el recurso de aceptar la concesión del alta definitiva, bajo su estricta responsabilidad. Por todo ello, la política de egreso otorgaba a los médicos el poder de decisión sobre el alta, pero tenían a las familias como artífices e hipotéticos responsables de los enfermos mentales una vez que abandonaban la institución.

Este asunto de la responsabilidad preocupaba especialmente a los facultativos de la Castañeda. En 1947, el Dr. Leopoldo Salazar Viniegra defendió la promulgación de una ley para los alienados en la Academia de Ciencias Penales como una necesidad para justificar el encierro de aquellos individuos que podían ser peligrosos para el medio social y familiar. Pero también servía para proteger a la profesión médica ante el ejercicio de las potestades del "responsable legal." Término que según Salazar Viniegra era inventado para el uso burocrático del hospital, pero que "en realidad no era "ni responsable", "ni legal tampoco." Para justificar tal afirmación expuso que: "a juicio y capricho de tales "responsables," quedaba la salida de los alienados contrariando a la opinión médica que señalaba al sujeto como peligroso y a quienes por motivos de seguridad y de su propio beneficio había que retenerse" ${ }^{67}$.

Y describió elocuentemente una situación a la que frecuentemente se enfrentaban los facultativos a la hora de dar de alta a un interno. Según Salazar en los externamientos caprichosos se manifestaban las pugnas familiares originadas por la "ignorancia supersticiosa" y se daba el caso de la esposa que internaba al marido "por trastornos perfectamente ostensibles" como elementos persecutorios, delirios y celos. $Y$ al cabo del tiempo se presentaban los familiares del paciente, generalmente la madre o los hermanos, quienes no admitían que su pariente se encontraba trastornado, "ni menos, loco, según la expresión vulgar y generalizada." $Y$ estas personas atribuían intenciones "avisas" a la esposa para deshacerse del marido y la acusaban de haberle hecho objeto de "algún mal", "embrujamiento" o "enyerbado". Y ante eso, Salazar afirmaba que poco se podía hacer con persuasión médica, pues se trataban con frecuencia de personas de alguna cultura o posición social. 
Y, en su opinión, lo que más afectaba a los médicos y a la asistencia pública era que la incomprensión y las creencias supersticiosas originaban escándalos cuando surgían "espontáneos, ingenuos o interesados defensores de los alienados" a los "que se suponen objeto de secuestro". Y propuso que el tutor o curador de los alienados fuera un médico alienista. $Y$ concluyó que: "Sería inútil mostrarse demasiado riguroso en retener internados a numerosos pacientes cuando no fuera absolutamente indispensable, conociendo como conocemos la deplorable insuficiencia de nuestro único manicomio general" ${ }^{\prime 68}$.

Este testimonio resulta esclarecedor de la situación a la que se enfrentaban los médicos del Manicomio General al momento de decidir si concedían el alta por petición familiar. Para empezar, no había un marco legal que protegiera la práctica de los facultativos, para continuar, la asistencia pública los presionaba para que dieran el mayor número de altas y, para terminar, muchos de ellos no estaban convencidos de conceder el egreso solo con el mejoramiento de los síntomas. Más si en el manicomio estaban recibiendo tratamiento que en su opinión estaba siendo eficaz y no debían ser dados de alta hasta que se encontraran en condiciones de ser verdaderamente útiles para la sociedad. Según algunos facultativos, había casos en los que los externados estaban en condiciones de vivir en familia, pero necesitaban tratamiento y vigilancia médica y ante la imposibilidad de negarse, intentaban dar recomendaciones para garantizar el bienestar de los pacientes que iban a abandonar el establecimiento. Sirva de ejemplo el Dr. García Diego, encargado del pabellón de reos y agitados en 1948, quien expuso que los internos que habían sido dados de alta para vivir con sus familias debían hacerlo bajo un asesor psiquiátrico y con terapia ocupacional ${ }^{69}$. Otros únicamente valoraban aspectos más formales como si sabía leer, escribir, si eran laboriosos en los trabajos que hacían en el manicomio o se portaban bien en la escuela del establecimiento ${ }^{70}$.

En el intento de paliar el problema de las salidas anticipadas de los internos, se envió una circular a los familiares informando de las disposiciones reglamentarias para evitar el prejuicio de la interrupción del tratamiento médico por parte de los familiares que insistían, según la opinión de los facultativos, en externar a su enfermo precipitadamente y sin conocer la opinión del médico encargado. Quien a su juicio era el único capacitado para opinar si era o no peligrosa la salida para la salud del enfermo. En caso de solicitar el permiso o el alta, si el médico no estaba de acuerdo, podía negársele y si la familia insistía se le concedía el alta definitiva bajo su estricta responsabilidad. Y, adicional- mente, necesitaban presentar una responsiva médica de algún otro doctor que se comprometiera a hacerse cargo del paciente en su domicilio o cualquier otro lugar. Además, se informó a las familias de que había un reglamento y que era imposible hacer excepciones ${ }^{71}$.

A pesar de la masificación, a finales de los años 50, todavía algunos médicos querían limitar los permisos y las salidas por petición familiar. Ya que los médicos de la institución seguían confiando en su capacidad de curar la enfermedad mental y eran reticentes a la hora de conceder permisos y altas, pues entendían que una salida prematura podía ser un obstáculo para la futura recuperación de sus pacientes. Sirva de ejemplo como, el jefe del pabellón de observación propuso que los familiares o responsables legales firmaran una cláusula al ingresar el paciente en el que se comprometían a no externarlo hasta un mes después de la fecha de internación. Tiempo que el jefe consideraba que era mínimo para la buena observación y para la iniciación de algún tratamiento. Esta medida, asimismo, pretendía evitar "tanto trabajo inútil" que quedaba cortado cuando los familiares usando "un derecho" que no podían manejar por sí mismos, solicitaban el alta. Y, además, sugería que no se concediera la salida definitiva, ni permisos sin que el familiar hubiera hablado con el médico y éste le hubiera informado del estado del paciente ${ }^{72}$.

Los problemas con la masificación y la búsqueda de soluciones a partir de los egresos continuaron hasta el cierre de la Castañeda. En abril de 1967, el Dr. Guillermo Calderón, de la Dirección de Salud Mental, envió un escrito al director del manicomio el Dr. Mario Fuentes Delgado. Calderón siguió las órdenes del profesor Caritino Maldonado, oficial mayor de la secretaría, y ordenó que dispusiera lo necesario para que el director del manicomio hiciera una estricta vigilancia sobre el número de enfermos que se encontraban internados en el hospital. Ya que, solamente se contaba con 2,600 camas en los nuevos hospitales y el número de enfermos que se alojaban en ese nosocomio, rebasaba en una forma considerable este número. Y a fin de poder modificar la situación, pidió cooperación a los médicos del establecimiento para que se diera el mayor número de altas posibles y que solamente se internaran los casos de emergencia absoluta, debiendo ser los demás canalizados a la consulta externa. Según el Dr. Mario Fuentes, el 17 de abril de 1967, el cupo de 2600 camas que iban a estar disponibles fuera del Manicomio General ya resultaba insuficiente, puesto que este número estaba excedido en 300 personas $^{73}$. 


\section{CONSIDERACIONES FINALES}

Aun cuando resulta complicado analizar el proceso de egreso de los enfermos mentales del Manicomio General de la Castañeda, pensamos que la información aquí presentada muestra que, a pesar de que la externación de los pacientes fue considerada por los responsables del manicomio y de la asistencia pública básicamente como un problema familiar, no bastaba con la implicación de los parientes para que los enfermos restablecidos o en remisión salieran del nosocomio y no volvieran a reingresar en él. Los ex asilados debían adaptarse a una vida fuera del manicomio, con los retos que esto suponía para ellos, sus familiares y para la propia sociedad mexicana.

De igual manera, las fuentes que hemos analizado muestran que en la salida de los enfermos del nosocomio se conjugaban varios intereses encontrados. La asistencia pública tenía la necesidad de dar de alta al mayor número posible de internos para tener espacio disponible para cumplir con las solicitudes de ingreso y rebajar los gastos de las arcas públicas, pero se oponían a ellas cuando la "peligrosidad" del enfermo mental se hacía visible ante la opinión pública por las quejas de los familiares o por eventos protagonizados por los ex asilados de la Castañeda. Por otra parte, los médicos y las autoridades precisaban de la responsabilidad familiar para que acogieran a los enfermos externados, pero sabían que estaba en riesgo su credibilidad profesional si la irresponsabilidad de los parientes o su falta de capacidad impedían la reinserción del paciente al medio familiar y social, aunque los médicos y funcionarios afirmaran que el enfermo estaba

\section{NOTAS AL FINAL}

1 Archivo Histórico de la Secretaría de Salud (AHSSA), F-BP, S-Imp., Se-H, Lg. 23, foja f.9, 1937-1938.

2 El Manicomio General de la Castañeda dependió de instancias gubernamentales cada vez más burocratizadas y complejas, primero de la Beneficencia Pública (1877-1937), después de la Secretaría de Asistencia Pública (1937-1943), finalmente de la Secretaría de Salubridad y Asistencia (19431968.) A efectos de redacción se utilizará en un sentido amplio la categoría "asistencia pública" cuando se haga referencia a la labor de las distintas dependencias gubernamentales implicadas en el sostenimiento de la Castañeda durante el periodo propuesto.

3 En esta investigación se ha analizado reglamentos internos, anteproyectos, cartas y oficios entre la dirección del Manicomio General y la asistencia pública, informes de labores técnicas, administrativas y comunicaciones de los responsables de los diversos departamentos que componían el nosocomio, listados de pacientes y minutas de los directores de curado, en remisión y podía vivir fuera de los muros del nosocomio.

En definitiva, una vez que los asilados de la Castañeda dejaban la institución, si no tenían a nadie apto que los recibiera en su entorno doméstico y que supervisaran sus visitas a los consultorios externos se rompía la cadena de cuidado y custodia. Y esa ausencia de vigilancia y sostenimiento podía dejar al descubierto las carencias y dificultades de las instituciones encargadas del cuidado y del tratamiento de los enfermos mentales. Las instituciones, por su parte, se veían desbordadas en esta labor de vigilar y dar seguimiento clínico a los enfermos externados. $Y$, con esta saturación de ex pacientes psiquiátricos eran vulnerables a la mala prensa. Situación que desencadenaba las suspicacias de los funcionarios de la asistencia pública hacia los psiquiatras, a los que acusaban del mal funcionamiento del Manicomio General. Acusaciones que eran respondidas por los responsables de esta institución culpando, a su vez, a las familias de los internos de ser las causantes de la masificación al no facilitar los egresos de sus deudos.

En resumen, estos intereses opuestos alimentaban las contradicciones, las desconfianzas y los conflictos entre los médicos y los funcionarios de la asistencia pública. Problemas que, en última instancia, eran fruto de las muchas deficiencias en el funcionamiento del nosocomio y de la insuficiencia de recursos que la asistencia pública destinaba al egreso de los pacientes y a su reinserción a la sociedad mexicana. Pero, sobre todo, eran resultado de una lucha contra la masificación que superaba a los médicos y a los funcionarios de la asistencia pública.

los pabellones emitidos entre 1929 y 1958 y que se encuentran resguardados en el Archivos Histórico de la Secretaría de Salud en la Ciudad de México.

4 Reglamento interno del Manicomio General, México, 16 de julio de 1913, AHSSA, F-BP, S-EH, Se- MG, Lg. 3, Exp. 25, pp. 2, 13, 14, 1913

5 Reglamento interno del Manicomio General, México, 1925, AHSSA, F-MG, S-Adm., caja 12, Exp. 5, f.89, 1925. Los artículos 37 y 38 hacen referencia al egreso de pacientes y corresponden a las páginas 22 y 23 del documento.

6 F-MG, S-Adm., C.1, Exp. 4, 1935.

7 En el expediente del F-MG, S-Adm., C.1, Exp. 4, 1945.

8 Datos para el informe de labores técnicas y administrativas que se desarrollan, 15 de marzo de 1956, firmado por el Dr. José Chávez Almazán. AHSSA, F-MG, S-Adm., Caja 12, Exp. 1, 1956.

9 En relación con el uso de la demografía psiquiátrica para analizar las características sociodemográficas de los internos de los manicomios, Tierno (2008). 
10 La selección había sido realizada a partir de los expedientes clínicos y contenía información relevante para el manicomio y el departamento de asistencia pública como fecha de ingreso, edad, diagnóstico, nombre y dirección de los responsables del interno. De 97 asilados, 14 provenían del departamento de trabajadores $B, 8$ de trabajadores $A, 45$ del pabellón de epilépticos, 16 del de neuro sifilíticos, 11 "toxifrénicos" y 3 eran pensionistas.

11 AHSSA, F-MG, S-Adm., Caja 9, Exp. 2, 1940.

12 Escrito de la trabajadora social Dolores Rodríguez informando que dos enfermos iban a ser trasladados a la Granja de Tlalpan y otro más a la Escuela Orientación para Varones, 13 de abril de 1950, AHSSA, F-MG, S- Adm., Caja 12, Exp. 1, 1950.

13 Oficio de marzo de 1956, F-MG, S-Adm., Caja 12, Exp. 1, 1956.

14 Escrito del director General de la Sociedad de Beneficencia Española enviado al director del Manicomio General, 25 de mayo de 1939, AHSSA, F-MG, S-Adm., Caja 11, Exp. 27, 1939.

15 Escritos del 6 de octubre y 10 de octubre de 1932, remitidos ambos por el Dr. Manuel Guevara Oropeza director del Manicomio General al Encargo de la oficina de admisión. Y escrito del 8 de noviembre de 1932 de la oficina de admisión haciendo referencia al oficio número 160 dirigido al director del Manicomio General. AHSSA, F-MG, S-Adm., Caja 9, Exp. 2, 1932.

16 AHSSA, F-MG, S-E.C., Caja 1, Exp.30, 1933.

17 Informe de Arturo Pierce, oficial $1^{\circ}$ encargado de la Oficina de Admisión, sobre enfermos dados de alta y los que habían sido enviados por el consultorio, México DF, 5 de junio de 1933, AHSSA, F-MG, S-Adm., Caja 10, Exp.15, 1933.

18 Escrito del director del manicomio general, Dr. Alfonso Millán, para el director general de la Beneficencia Pública, 7 de marzo de 1938, sobre el envío de enfermos sin cumplir con los requisitos legales y administrativos necesarios, F-MG, S-Adm., Caja 16, Exp. 6, 1938.

19 El Dr. Salvador Navarro del Dpto. médico de la Beneficencia Pública escribió que las familias daban información falsa de dónde vivían. F-MG, S-Adm., Caja 10, Exp. 15, 1933.

20 Y como ha demostrado Cristina Sacristán (2017, p. 9) el motivo más importante de egresos, entre 1910 y 1968, fue la solicitud familiar. Esta ascendió a un $29.38 \%$, más que por fallecimiento $(24.20 \%)$ o por remisión del padecimiento $(13.8 \%)$ (Sacristán, 2017, p. 9), lo que implica que cerca de un $30 \%$ de los familiares querían que su deudo volviera.

21 AHSSA, F-MG, S-Adm., Caja 9, Exp. 2, 1938.

22 Escrito del Dr. Salvador M. Navarro dirigido al Inspector de Policía, 6 de julio de 1933. AHSSA, F-MG, S-Adm., Caja 11, Exp. 27, 1933.

23 Oficio del Jefe de Dpto. de Asistencia Médica, 18 de octubre de 1943. AHSSA, F-MG, S-Adm., Caja 9, Exp. 2, 1943.

24 Escrito del Dr. Salvador M. Navarro dirigido al Inspector de Policía, 6 de julio de 1933. AHSSA, F-MG, S-Adm., Caja 11, Exp. 27, 1933.

25 Propuesta para la creación de una cooperativa que diera apoyo económico a los enfermos trabajadores que fueran dados de alta en 1935, México DF, 12 de septiembre de 1935, AHSSA, Fondo Manicomio General, Sección Administración, Caja 19, Expediente 16. Proyecto para el funcionamiento de los ta-
Ileres del Manicomio General presentado por Ernesto Briseño al director del Manicomio General, México DF, s/f, AHSSA, Fondo Manicomio General, Sección Administración, Caja 19, Expediente 16, p.3; Plan de reorganización de la caja de ahorros para que los enfermos recibieran una cantidad devenida por su trabajo, México DF, s/f, AHSSA, Fondo Manicomio General, Sección Administración, Caja 19, Expediente 16, pp.4-5.

26 En México, la cronicidad de la enfermedad mental y el fracaso del encierro manicomial como modelo terapéutico han sido estudiadas de forma esencial por Cristina Sacristán (2001, 2002, 2003, 2005a, 2005b, 2008). Para otros contextos históricos: Lanteri-Laura (1972), Gauchet y Swain (1980), Campos (2001), Eraso, (2002).

27 El tema de las granjas hospital también ha sido trabajados también por Tejada (1967), De la Fuente y Campillo (1976), Ramos (1998), Rodríguez y Castañeda (2013).

28 F-MG, S-Adm., C.1, Exp. 4, 1944.

29 Lista del pabellón de epilépticos, 27 de mayo de 1936 y Lista del pabellón de epilépticos 14 de enero de 1937. AHSSA, F-MG, S-Adm., Caja 9, Exp.2, 1936-1937.

30 Proyecto de reglamento para el funcionamiento de la oficina de admisión sobre el movimiento de enfermos, 1935. AHSSA F-MG, S-Adm., Caja 20, Exp. 13, 1935.

31 Sobre las trabajadoras sociales en México en los años 30 del siglo XX, María Dolores Lorenzo (2018, pp. 713-746).

32 Proyecto de organización de un servicio social en el Manicomio General, por Mathilde Rodríguez Cabo, AHSS, F-SSA, SeSSA, Lg. 3, Exp. 14, 1944.

33 Memorándum firmado por el director del Manicomio General Dr. Leopoldo Salazar Viniegra, México DF, 4 de agosto de 1947, AHSSA, F-MG, S-Adm., Caja 9, Exp. 2, 1947.

34 Carta del Dr. Ricardo Labardini Nava, director general de Asistencia, dpto. de Asistencia Neuropsiquiátrica al director del Manicomio General Dr. Samuel Ramírez Moreno, 22 de septiembre de 1948. AHSSA, F-MG, S-Adm., Caja 12, Exp. 1, 1948.

35 AHSSA, F-MG, S-Adm., Caja 9, Exp. 2, 1948.

36 AHSSA, F-MG, S-Adm., Caja 12, Exp. 1,1948.

37 Mathilde Rodríguez Cabo, "proyecto de organización de un servicio social en el Manicomio General" (1944), AHSSA, F-Subsecretaría de Salubridad y Asistencia, S-Subsecretaría de Salubridad y Asistencia, Caja 3, Exp. 14, 1944.

38 El tema de los consultorios externos que brindaban consultas a los pacientes aquejados de algún tipo de enfermedad mental, primero en el manicomio y después fuera del establecimiento, se trata de manera tangencial en este artículo puesto que el objeto de la investigación es analizar el proceso de egreso en su vertiente familiar. Cristina Sacristán (2017a) realizó una valiosa aproximación a las clínicas externas a partir del consultorio que se abrió en el pabellón central del Manicomio General. Sin embargo, sería muy interesante y necesario que se realizara un estudio en profundidad de las clínicas externas que explicara cuáles eran los padecimientos más habituales que se atendían en estos dispensarios y de qué manera recibían tratamiento. Asunto que siguen abierto para investigaciones futuras de historia de la psiquiatría en México en el siglo XX.

39 Oficio del departamento médico de la Beneficencia Pública dirigido al director del manicomio general de fecha 25 de 
mayo de 1933, AHSSA, F-MG, S-ADM., Caja 10, Exp. 15, 1933.

40 Misiva del Dr. Guevara Oropeza director del Manicomio General al jefe del Departamento Médico del Beneficencia Pública, 15 de junio de 1933. AHSSA, F-MG, S-Adm., Caja 10, Exp.15, 1933.

41 Escrito de Salvador Navarro jefe del Departamento Médico de la Beneficencia Pública al Dr. Guevara Oropeza, 27 de junio de 1933. AHSSA, F- MG, S-Adm., Caja 10, Exp. 15, 1933.

42 Archivo Histórico de la Secretaría de Salud (AHSSA), F-BP, S-Imp., Se-H, Lg. 23, foja f.9, 1937-1938.

43 Informe sobre un estudio de los casos clínicos que pueden ser externados colaborando con los médicos del Manicomio General enviado al jefe del Departamento Médico de la Beneficencia Pública, F-MG, S-Adm., caja 10, Exp.15, 1933.

44 F-MG, S-Adm., C.1, Exp. 4, 1944.

45 "Ante Proyecto de reglamento y funcionamiento de la admisión del Manicomio General”, F-MG, S-Adm., Caja 20, Exp. 13, pp.1, 4-5, 6-8, 1944.

46 "Ante Proyecto de reglamento y funcionamiento de la admisión del Manicomio General", F-MG, S-Adm., Caja 20, Exp. 13, 1944.

47 Documento del Dpto. de Asistencia Neuropsiquiátrica de fecha 27 de agosto de 1948. AHSSA, F- MG, S- Adm., Caja 9, Exp. 2, 1948.

48 A partir de los años 30, varias consultas externas fueron establecidas. En 1948, una de estas consultas externas estaba situada en el Hospital Juárez y otra en el Centro de Adiestramiento y Dispensario Central Antivenéreo situado en la calle de Tolsá. Escrito del Dr. Ricardo Labardini Nava, director del Departamento de Neuropsiquiatría de la Dirección General de Asistencia, dirigido al director del Manicomio General, 27 de agosto de 1948. AHSSA, F-MG, S-Adm., Caja 12, Exp. 1, 1948.

49 AHSSA, F-MG, S-Adm., Caja 12, Exp. 1, 1948.

50 En el contexto de descentralización de la Castañeda se crearon otras instituciones que ayudaron a mejorar la situación de los enfermos crónicos y agudos. Como resultado de esta política se inauguraron seis granjas hospitales (1960-1964), tres hospitales campestres (1966-1967) para enfermos con capacidad de sanación que eran similares a las granjas porque buscaban la curación de los internos, pero sin la connotación de realizar labores agrícolas, un albergue (1967) y dos hospitales para enfermos agudos (1966) (Sacristán, 2013; Vicencio, 2014; Ríos, Sacristán, Ordorika, López, 2016). Instalaciones que entre varias funciones debían servir para desahogar el Manicomio General.

51 Escrito del encargado del pabellón de epilépticas y oligofrénicas dirigido al director del Manicomio General, 8 de mayo de 1935, AHSSA, F-MG, S-Adm., Caja 9, Exp. 2, 1935.

52 AHSSA, F-MG, S-Adm., Caja 9, Exp.2, 1935

53 Minuta del jefe de pabellón de epilépticas y oligofrénicas del Manicomio General, México DF, 8 de mayo de 1935 y Minuta del 27 de mayo de 1936, AHSSA, F-MG, S-Adm., Caja 9, Exp. 2, 1936.

54 Oficio del director del Manicomio General Dr. Manuel Guevara Oropeza, México DF, 15 de junio de 1933, AHSSA, F-MG, S-Adm., Caja 10, Exp. 15, 1933.
55 Escrito de la Junta de la Beneficencia Pública dirigido al director de la Castañeda con fecha 27 de agosto de 1935. AHSSA F-MG, S-Adm., Caja 9, Exp. 2, 1935.

56 Escrito del director del MG Alfonso Millán dirigido a los médicos del servicio médico. 3 de agosto de 1938. AHSSA, F-MG, S-Adm., Caja 9, Exp.12, 1938.

57 AHSSA, F-MG, S-Adm., Caja 12, Exp. 1, 1942.

58 Lista de pacientes en remisión (1948). AHSSA, F-MG, S-Adm. Caja 12, Exp. 1, 1948.

59 Escrito del Dr. Clemente Robles, jefe del departamento de asistencia médica de la Dirección General de la Asistencia Pública al director del Manicomio General, México DF, 29 de septiembre de 1943, AHSSA, F- MG, S-Adm., Caja 9, Exp. 2, 1943.

60 Escrito del director del Manicomio General al Jefe de Dpto. de Asistencia Médica, 4 de octubre de 1943. AHSSA, F-MG, S-Adm., Caja 9, Exp. 2, 1943.

61 Oficio del Jefe de Dpto. de Asistencia Médica, 18 de octubre de 1943. AHSSA, F-MG, S-Adm., Caja 9, Exp. 2, 1943.

62 Escrito del director del Manicomio General al Jefe de Dpto. de Asistencia Médica, 22 de octubre de 1943. AHSSA, F-MG, S-Adm., Caja 9, Exp.2, 1943.

63 Oficio del Jefe de Dpto. de Asistencia Médica, 28 de octubre de 1943. AHSSA, F-MG, S-Adm., Caja 9, Exp. 2, 1943.

64 Departamento de Asistencia Médica a Dirección de Manicomio General, 7 de marzo de 1944, AHSSA, F-MG, S-Adm., Caja 9, Exp. 2, 1944.

65 Propuesta para la creación de una cooperativa que diera apoyo económico a los enfermos trabajadores que fueran dados de alta en 1935, México DF, 12 de septiembre de 1935, AHSSA, F-MG, S-Adm., Caja 19, Exp.16, 1935. Proyecto para el funcionamiento de los talleres del Manicomio General presentado por Ernesto Briseño al director del Manicomio General, México DF, s/f, AHSSA, F-MG, S-Adm., Caja 19, Exp. 16, p.3, 1935-1938; Plan de reorganización de la caja de ahorros para que los enfermos recibieran una cantidad devenida por su trabajo, México DF, s/f, AHSSA, F-MG, S-Adm., Caja 19, Exp.16, pp.4-5, 1935-1938.

66 Documento de 29 de julio de 1940, AHSSA, F-MG, S-Adm., Caja 9, Exp.2, 1940.

67 AHSSA, F-MG, S-Adm., Caja 43, Exp. 16. "Legislación de alienados" por Leopoldo Salazar Viniegra, Pp.13-14, 1947.

68 AHSSA, F-MG, S-Adm., Caja 43, Exp. 16. "Legislación de alienados" por Leopoldo Salazar Viniegra, Pp.13-14, 19, 1947.

69 AHSSA, F-MG, S-Adm., Caja 43, Exp. 16. "Legislación de alienados" por Leopoldo Salazar Viniegra, Pp.13-14, 19, 1947.

70 Escrito del Dr. Alfonso Pérez Montero, jefe del departamento de psiquiatría infantil, al director del Manicomio General Dr Alfonso Millán. AHSSA, F-MG, S-Adm., Caja 9, Exp. 12, 1948.

71 AHSSA, F-MG, S-Adm., Caja 12, Exp. 1,1948.

72 Proposiciones para poner en orden la salida de las asiladas. Escrito del jefe de pabellón de observación al director del Manicomio General, 22 y 29 de octubre de 1958, AHSSA, F- MG, S-Adm., Caja 9, Exp. 2, 1958.

73 AHSSA, F-MG, S-Adm., Caja 20, Exp. 13. Para un mayor conocimiento sobre el proceso de cierre de la Castañeda, Vicencio, 2017, pp. 31-88. 


\section{BIBLIOGRAFÍA}

Campos, Ricardo (2001), “De la higiene del aislamiento a la higiene de la libertad. La reforma de la institución manicomial en Francia (1860-1940)", Frenia, Revista de Historia de la Psiquiatría, 1, (1), pp.38-64.

De la Fuente, Ramón; Campillo, Carlos (1976), “La psiquiatría en México. Una perspectiva histórica" Gaceta Médica de México, vol. III, (5), pp. 421-436.

Eraso, Yolanda, (2002), “El trabajo desde la perspectiva psiquiátrica. Entre el tratamiento moral y el problema de la cronicidad en el Manicomio de Oliva de Córdoba en las primeras décadas del siglo XX", Cuadernos de historia, serie economía y sociedad, 5, pp.33-63.

García Canal, María Inés (2008), “La relación médico-paciente en el Manicomio de La Castañeda entre 1910-1920, tiempos de revolución", Nuevo Mundo Mundos Nuevos, [en línea], disponible en: http://nuevomundo.revues.org//index14422. html, [consultado: 27/09/2018]

Gauchet, Marcel ; Swain, Gladys (1980), « La practique l'esprit humain ". L'institution asilaire et la révolution démocratique, París, Gallimard, pp.88-92.

Lanteri-Laura, George (1972), « La chronicité dans la psychiatrie moderne française. Note d'histoire théorique et sociale, $A n-$ nales Économes Sociétés, Civilisations, 3, pp. 548-568.

Lorenzo, María Dolores (2018), "Las trabajadoras sociales en la década de 1930, asistir a los pobres y servir al Estado", Historia Mexicana, vol. LXVIII, 2, pp. 713-746.

Ramos, Alejandro, (1998), “El manejo de pacientes crónicos en el hospital psiquiátrico de Jalisco", Relaciones, 19, (74), pp. 170-199.

Ríos, Andrés (Coord.) (2017), Los pacientes del Manicomio de la Castañeda y sus diagnósticos. Una historia de la clínica psiquiátrica en México, 1910-1968, México, UNAM, Instituto Mora.

Ríos, Andrés; Sacristán, Cristina; Ordorika, Teresa; López, Ximena (2016), "Los pacientes del Manicomio La Castañeda y sus diagnósticos. Una propuesta desde la historia cuantitativa (México, 1910-1968)", Asclepio 68 (1): p.136. doi: http://dx. doi.org/10.3989/asclepio.2016.15

Ríos, Andrés (2009), La locura durante la Revolución Mexicana. Los primeros años del Manicomio General La Castañeda, 1910-1920, México, El Colegio de México, p.27.

Ríos, Andrés (2010), “Indigencia, migración y locura en el México posrevolucionario" Historia Mexicana, 59, (4), (236), pp. 1295-1337.

Rodríguez, Ana Cecilia y Castañeda, Gabriela (2013), "El Hospital Granja y la Escuela Granja Bernardino Álvarez: antecedentes del Instituto Nacional de Neurología y Neurocirugía", Revista de Investigación Clínica, 65(6), pp. 524-536.

Sacristán, Cristina (1998), “¿Quién me metió en el manicomio? El internamiento de enfermos mentales en México, siglos XIX y XX", Relaciones. Estudios de Historia y Sociedad, primavera de 1998, XIX, (74), pp. 201-233. [en línea], disponible en: https://www.colmich.edu.mx/relaciones25/files/revistas/074/MariaCristinaSacristan.pdf
Sacristán, Cristina (2001), “Una valoración sobre el fracaso de manicomio de La Castañeda como institución terapéutica, 1910-1944", Secuencia. Revista de historia y ciencias sociales, 51, pp. 91-120.

Sacristán, Cristina (2002), “Entre curar y contener. La psiquiatría mexicana ante el desamparo jurídico, 1870-1944", Frenia. Revista de historia de la psiquiatría, II, (2), pp. 61-80 [en línea], disponible en: http://www.revistaaen.es/index.php/ frenia [consultado: 25/08/2019]

Sacristán, Cristina (2003), "Reformando la asistencia psiquiátrica en México. La Granja de San Pedro del Monte: los primeros años de una institución modelo, 1945-1948", Salud Mental. Revista del Instituto Nacional de Psiquiatría, 26, (3), pp. 5765. [en línea], disponible en.

Sacristán, Cristina (2005a), "Una Locópolis de Mixcoac" en una encrucijada política. Reforma psiquiátrica y opinión pública, 1929-1933", en Cristina Sacristán y Pablo Picato, coordinadores en Actores, espacios y debates en la historia de la esfera pública en la ciudad de México, México, Instituto Mora, pp. 199-232.

Sacristán, Cristina (2005b), “Por el bien de la economía nacional. Trabajo terapéutico y asistencia pública en el Manicomio de La Castañeda de la ciudad de México, 1929-1932", História, Ciências, Saúde, Manguinhos, 12, (3). pp. 675-692. [en línea], disponible en: http://www.scielo.br/pdf/hcsm/ v12n3/03.pdf [consultado: 3/09/2019]

Sacristán, Cristina (2008), “Para integrar a la nación. Terapéutica deportiva y artística en el Manicomio de La Castañeda en un momento de reconstrucción nacional, 1920-1940", en Claudia Agostoni (ed.), Curar, sanar y educar. Enfermedad y sociedad en México, siglos XIX y XX, México, Instituto de Ciencias Sociales y Humanidades "Alfonso Vélez Pliego» de la Benemérita Universidad Autónoma de Puebla, Instituto de Investigaciones Históricas de la UNAM, pp. 99-123.

Sacristán, Cristina (2009), "La locura se topa con el manicomio. Una historia por contar", Cuicuilco. Revista de la Escuela Nacional de Antropología e Historia, 16, (45), pp. 163-188.

Sacristán, Cristina (2010), "La contribución de La Castañeda a la profesionalización de la psiquiatría mexicana, 1910-1968", Salud Mental, 33, (6), noviembre-diciembre de 2010, pp. 473-480.

Sacristán, Cristina (2017), "Curar y custodiar. La cronicidad en el Manicomio de la Castañeda, Ciudad de México, 1968", Asclepio. Revista de Historia de la Medicina y de la Ciencia, 69 (2), p.193, http://dx.doi.org/10.3989/asclepio.2017.16 Consultado: $14 / 09 / 2019]$

Sacristán, Cristina (2017a), "La clínica psiquiátrica en el pabellón central.", en Los pacientes del Manicomio de la Castañeda y sus diagnósticos. Una historia de la clínica psiquiátrica en México, 1910-1968, pp.41-70.

Tejada, Carlos (1967), "Los hospitales granja”, Salud Pública de México, época V, vol. IX, (4), pp. 587-590.

Tierno, Raquel (2008), “Demografía psiquiátrica y movimientos de la población del manicomio nacional de Santa Isabel (1931-1952)" Frenia, Revista de Historia de la Psiquiatría,8, pp. 97-130. 
Urías, Beatriz (2004), “Degeneracionismo e higiene mental en el México posrevolucionario (1920-1940)" Frenia, Revista de Historia de la Psiquiatría, 4, (2), pp. 37-67.

Valdés, Marisa (1995), “La salud mental en el Porfiriato. La Construcción de la Castañeda", tesis de licenciatura en Historia, México, Universidad Autónoma de México.

Vicencio, Daniel (2014), “La Operación Castañeda. Una reforma asistencia de la psiquiatría en México, 1940-1968", te- sis de maestría en Historia, México, Universidad Nacional Autónoma de México.

Vicencio, Daniel (2017), “'Operación Castañeda'. Una historia de los actores que participaron en el cierre del Manicomio General, 1940-1968" en Andrés Ríos Molina (Coord.) La psiquiatría más allá de sus fronteras: instituciones y representaciones en el México contemporáneo, México, UNAM, pp. 31-88. 